\title{
Thoracoscopic sympathicolysis for essential hyperhidrosis: effects on pulmonary function
}

\author{
M. Noppen, W. Vincken
} Thoracoscopic sympathicolysis for essential hyperhidrosis: effects on pulmonary func-
tion. M. Noppen, W. Vincken. CERS Journals Ltd 1996.

ABSTRACT: Bilateral interruption of the upper dorsal sympathetic chain at the D2 and D3 level represents the only permanent cure for essential hyperhidrosis. Following surgical sympathectomy, significant and symptomatic changes in pulmonary function have been observed. Since functional effects of the surgical intervention cannot be excluded, we wondered whether such alterations also occurred after thoracoscopic sympathicolysis; these should then be attributable to the surgical denervation itself.

Pulmonary function tests (PFTs), including spirometry and body plethysmographic measurement of lung volumes and airway resistance and conductance, were compared before and 6 weeks after thoracoscopic sympathicolysis in 47 patients. In order to virtually exclude any effects of thoracoscopy on the test results, PFTs were repeated 6 months after thoracoscopic sympathicolysis in 35 patients.

Essential hyperhidrosis was completely relieved in all patients, thereby confirming the interruption of the D2-D3 sympathetic chain. None of the patients developed respiratory symptoms after thoracoscopic sympathicolysis. Forced expiratory volume in one second (FEV1) (-3\%), forced expiratory flow after exhaling $75 \%$ of vital capacity (FEF75) (-8\%) and total lung capacity (TLC) $(-3 \%)$ were slightly but significantly reduced at six weeks after thoracoscopic sympathicolysis; whereas airway resistance $(R$ aw $)$ had increased $(+\mathbf{1 2 \%})$. After correction for the small decrease in lung volume (FEV1/forced vital capacity (FVC), specific airway resistance ( $\mathrm{s}$ Raw), specific airway conductance $(\mathrm{s} G$ aw) $)$ significant changes in "volume-dependent" PFT parameters were no longer observed. Smoking status had no influence on the reduction in FEF75. At 6 months after thoracoscopic sympathicolysis, TLC had returned to preoperative values, whereas FEF75 remained decreased $(-8.6 \%)$. The decrease in airway calibre was confirmed by small but significant changes in FEV1/FVC (-2\%) and $R$ aw $(+29 \%)$.

We conclude that thoracoscopic sympathicolysis in patients with essential hyperhidrosis causes only minimal and subclinical changes in pulmonary function secondary to a temporary small decrease in lung volume, which in turn is probably inherent to the thoracoscopic procedure. D2-D3 sympathicolysis, in itself, is responsible only for a small and permanent decrease in forced expiratory flow, which suggests that, at least in essential hyperhidrosis patients, airway bronchomotor tone is influenced by sympathetic innervation.

Eur Respir J., 1996, 9, 1660-1664.
Respiratory Division, Academic Hospital, AZ-VUB, University of Brussels, Brussels, Belgium.

\author{
Correspondence: M.M.P. Noppen \\ Respiratory Division \\ University Hospital AZ-VUB \\ 101 Laarbeeklaan \\ Brussels \\ Belgium
}

Keywords: Essential hyperhidrosis pulmonary function

sympathectomy

sympathetic innervation

thoracoscopy

Received: January 151996

Accepted after revision April 281996
Essential hyperhidrosis (EH) is a disorder characterized by excessive sweating of the palms of the hands and often the armpits and soles of the feet [1]. It is caused by a poorly understood overactivity of the sympathetic nervous system at the level of the D2 and D3 dorsal sympathetic ganglia [2]. Anatomical interruption of the sympathetic innervation at this level, preferably by minimally invasive techniques, such as percutaneous ablation or thoracoscopy, provides a permanent cure in patients with severe EH refractory to conventional treatment [3-5]. The D2 and D3 ganglia are, however, also in the direct pathway of the sympathetic innervation (arising from D1 to D6) of the central thoracic organs [6]. Therefore, D2-D3 sympathicolysis also causes a partial sympathetic denervation of the lungs. Although direct sympathetic innervation to bronchial smooth muscle in human lung is sparse
[7], sympathetic nerves may influence bronchial motor tone by modulating cholinergic neurotransmission in parasympathetic airway ganglia, especially when bronchomotor tone is increased [7,8], e.g. in asthma. Only two studies have described the effects on pulmonary function of surgical D2-D3 sympathectomy for EH: significant decreases in all lung volumes and maximal expiratory flows were observed, and were ascribed to sympathetic denervation $[9,10]$, although these results might, at least partially, be explained by concomitant phrenic nerve damage, extrapleural haematomas or segmental atelectasis, i.e. due to the consequences of surgery itself [7].

These postoperative changes are largely avoided by using thoracoscopic sympathicolysis (TS), a minimally invasive technique with no damage to phrenic nerve(s), lung, muscles, etc. TS therefore provides a better opportunity to 
study the effects of D2-D3 sympathicolysis itself on pulmonary function. We thus compared pulmonary function tests (PFTs), before and 6 weeks after TS in 47 patients with EH. In order to virtually exclude the effects of the thoracoscopic procedure itself, and to study the longterm effects of partial sympathetic denervation of the lungs, repeated tests 6 months after the intervention were obtained in 35 patients.

\section{Methods}

\section{Patient population}

Fifty consecutive patients with severe EH, refractory to medical treatment including application of topical anti-perspirants, oral anticholinergics and iontophoresis, (15 males, mean (SD) age 32 (8) yrs, range 16-45 yrs, and 35 females, mean (SD) age 27 (8) yrs, range 13-52 yrs) underwent TS from August 1993 to August 1994. A detailed medical history with special emphasis on respiratory or cardiac disease, and a complete physical examination were performed 1-2 weeks before TS. No cardiopulmonary medication was allowed prior to the study. Three patients $(6 \%)$ had a history of mild atopic asthma in childhood. They were currently free of symptoms and did not take any medication. Nine patients were current smokers and two patients were ex-smokers. One day before TS, chest radiography, electrocardiography (ECG), standard preoperative blood tests and pulmonary function tests (PFTs) were performed. PFTs were repeated 6 weeks later. All patients gave informed consent. The study protocol was approved by the Ethics Committee for Human Research at our institution. In 35 patients, repeat PFTs were obtained after 6 months. Twelve patients could not be re-examined at 6 months because of movement abroad (one patient), residing at too great a distance from the hospital (seven patients), and simple refusal (four patients). Age, sex and baseline PFT results in these 35 patients, however, did not differ from the original data in 50 patients (Student's t-test and Chi-squared tests; $\mathrm{p}>0.05)$. Informed consent was obtained from every patient.

\section{Pulmonary function tests}

Spirometry and flow-volume loops were measured in a Sensor Medics 2200 PFT unit (SensorMedics, Bilthoven, The Netherlands). At least three manoeuvres, with the two best being reproducible, were performed. Forced vital capacity (FVC) and forced expiratory volume in one second (FEV1) were required to be reproducible within 5\%, the highest value for each being recorded. Peak expiratory flow (PEF) and forced expiratory flow after expiration of $75 \%$ of the vital capacity (FEF75) were also measured, and the highest value recorded. Airway resistance ( $R$ aw) was measured using a constant volume body plethysmograph (Sensor Medics 6200 Autobox). Thoracic gas volume (functional residual capacity (FRC)) was measured simultaneously, enabling calculation of residual volume (RV) and total lung capacity (TLC), as well as specific airway resistance ( $\mathrm{s} R \mathrm{aw}$ ) relative to volume, and specific airway conductance ( $\mathrm{s} G \mathrm{aw}$ ) normalized for volume.

\section{Thoracoscopic sympathicolysis}

All interventions were performed under strict aseptic conditions in a fully equipped operating theatre. After premedication with midazolam $\left(0.1 \mathrm{mg} \cdot \mathrm{kg}^{-1}\right)$ and glycopyrrolate $(0.2 \mathrm{mg})$, patients were anaesthetized with propofol, alfentanil and atracurium. Intubation was performed with a single-lumen Hi-Lo jet endotracheal tube (Mallinckrodt $\AA$ ) and ventilation was assured using high frequency jet ventilation (Acutronic $®$ ) on both lungs. This ventilation mode allowed for sufficient lung collapse to gain easy access to the sympathetic nerves. After creation of a right-sided pneumothorax, a $7 \mathrm{~mm}$ trocar was introduced into the pleural cavity via the second intercostal space. The thoracoscope (Richard Wolf, Knitlingen, Germany) was introduced via the trocar, and the dorsal sympathetic chain was identified. An insulated biopsy forceps connected to a unipolar coagulation unit was then introduced via a second trocar, which was introduced $3-4 \mathrm{~cm}$ laterally from the first trocar, under direct vision. The sympathetic trunk was electrically transsected on the 2nd and 3rd dorsal rib heads, using 5-15 bursts of $60 \mathrm{~W}$. After re-expansion of the pneumothorax and skin closure, the same procedure was immediately performed on the left hemithorax. Mean (SD) duration of this bilateral procedure was 25 (8) $\mathrm{min}$ (range 20-40 min). Mean (SD) hospital stay was 2 (0.3) nights (range 1-3 nights), and mean duration of incapacity for work or school was 5 (1.3) (range 2-6) days.

\section{Statistical analysis}

Data are expressed as mean \pm SD values. Data before and after TS were compared using the paired t-test. Baseline PFT data and patient characteristics between the original 50 patients and the 35 patients studied at 6 months were compared using the two-tailed Student's ttest and Chi-squared analysis or Fisher exact test when indicated. In 35 patients, PFT data at baseline, 6 weeks and 6 months were compared using repeated measure analysis of variance (ANOVA). Comparison with baseline data was performed using Dunnett's test. Significance was accepted at a p-value less than 0.05 .

\section{Results}

In one patient, right-sided pneumothorax could not be performed because of extensive adhesions. In 49 patients, a bilateral one-time sequential thoracoscopic sympathicolysis could be performed, but two of these patients were lost for the 6 week PFT follow-up. Data for a 6 week comparison were, therefore, available in 47 patients.

Palmar hyperhidrosis was immediately and completely relieved in all patients $(100 \%)$, thereby confirming the complete anatomical interruption of the D2-D3 ganglia.

No patient experienced dyspnoea or any other respiratory symptom. The effects of TS on PFT variables obtained after 6 weeks are shown in table 1 . Small but significant decreases in mean FEV1 (-3\%) and TLC (-3\%) were observed, whereas FEF75 had disproportionately decreased $(-8 \%)$. Raw had increased by $12 \%$. After correction for the decrease in lung volume (FEV1/FVC, sRaw and sGaw) differences in airway resistance or conductance were no 
Table 1. - Changes in pulmonary function in 47 patients at 6 weeks after thoracoscopic sympathicolysis (TS)

\begin{tabular}{llcc}
\hline & & Baseline & 6 weeks after TS \\
\hline FVC & $\mathrm{L}$ & $4.73 \pm 0.85$ & $4.64 \pm 0.9$ \\
& $\%$ pred & $117 \pm 13$ & \\
FEV1 & $\mathrm{L}$ & $3.90 \pm 0.8$ & $3.79 \pm 0.78^{*}$ \\
& $\%$ pred & $112 \pm 12$ & \\
FEV1/FVC \% & $83 \pm 7$ & $82 \pm 7$ \\
FEF75 & $\mathrm{L} \cdot \mathrm{s}^{-1}$ & $2.02 \pm 0.71$ & $1.86 \pm 0.74 *$ \\
& $\%$ pred & $91 \pm 28$ & \\
PEF & $\mathrm{L} \cdot \mathrm{s}^{-1}$ & $7.83 \pm 1.56$ & $7.9 \pm 1.77$ \\
TLC & $\mathrm{L}$ & $5.87 \pm 0.98$ & $5.7 \pm 0.95^{*}$ \\
& $\%$ pred & $99 \pm 15$ & \\
$\mathrm{RV}$ & $\mathrm{L}$ & $1.09 \pm 0.35$ & $1.03 \pm 0.38$ \\
& $\%$ pred & $105 \pm 22$ & \\
$R$ aw & $\mathrm{cmH} \mathrm{H}_{2} \mathrm{O} \cdot \mathrm{L}^{-1} \cdot \mathrm{s}^{-1}$ & $2.73 \pm 0.99$ & $3.06 \pm 0.92^{*}$ \\
$\mathrm{~s} R$ aw & $\mathrm{cmH} \mathrm{H}_{2} \mathrm{O} \cdot \mathrm{s}^{-1}$ & $7.55 \pm 2.3$ & $7.87 \pm 2.1$ \\
$\mathrm{~s} G$ aw & $\mathrm{cmH} \mathrm{O}^{-1} \cdot \mathrm{s}^{-1}$ & $0.14 \pm 0.05$ & $0.14 \pm 0.05$ \\
& &
\end{tabular}

Values are presented as mean \pm SD. FVC: forced vital capacity; FEV1: forced expiratory volume in one second; FEF75: forced expiratory flow after expiration of $75 \%$ of the vital capacity; PEF: peak expiratory flow; TLC: total lung capacity; RV: residual volume; $R$ aw: airway resistance; $s R$ aw: specific airway resistance; s $G$ aw: specific airway conductance; $\%$ pred: percentage of predicted value. *: p<0.05 comparing value at baseline and 6 weeks after TS.

Table 2. - Changes in pulmonary function before, 6 weeks and 6 months after thoracoscopic sympathicolysis in 35 patients available for follow-up

\begin{tabular}{lclc}
\hline & Baseline & 6 weeks & 6 months \\
\hline FVC L & $4.72 \pm 0.87$ & $4.63 \pm 0.93$ & $4.67 \pm 0.9$ \\
FEV1 L & $3.88 \pm 0.68$ & $3.77 \pm 0.73^{*}$ & $3.76 \pm 0.72^{*}$ \\
FEV1/FVC \% & $82 \pm 7$ & $82 \pm 7$ & $81 \pm 8^{*}$ \\
FEF75 L·s & $1.97 \pm 0.77$ & $1.84 \pm 0.8^{*}$ & $1.8 \pm 0.8^{*}$ \\
$\mathrm{PEF} \mathrm{L} \cdot \mathrm{s}^{-1}$ & $7.72 \pm 1.56$ & $7.85 \pm 1.79$ & $7.71 \pm 1.81$ \\
$\mathrm{TLC} \mathrm{L}$ & $5.92 \pm 1.09$ & $5.72 \pm 1.08^{*}$ & $5.82 \pm 1.05$ \\
$\mathrm{RV} \mathrm{L}$ & $1.14 \pm 0.36$ & $1.06 \pm 0.41$ & $1.08 \pm 0.37$ \\
$R$ aw & $2.64 \pm 1.1$ & $3.07 \pm 1.01^{*}$ & $3.41 \pm 1.38^{*}$ \\
$\mathrm{cmH} \mathrm{H}_{2} \mathrm{O} \cdot \mathrm{L}^{-1} \cdot \mathrm{s}^{-1}$ & & & \\
$\mathrm{~s} R$ aw & $7.41 \pm 1.68$ & $7.72 \pm 1.75$ & $7.78 \pm 1.90$ \\
$\mathrm{cmH} \mathrm{H}_{2} \mathrm{O} \cdot \mathrm{s}$ & & & \\
$\mathrm{s} G \mathrm{aw}$ & $0.15 \pm 0.05$ & $0.14 \pm 0.06$ & $0.14 \pm 0.05$ \\
$\mathrm{cmH} \mathrm{H}_{2} \mathrm{O}-1 \cdot \mathrm{s}^{-1}$ & & & \\
\hline
\end{tabular}

Values are expressed as mean \pm SD. $*: p<0.05$ as compared to baseline values (ANOVA and Dunnett's test). ANOVA: analysis of variance. For further definitions see legend to table 1 .

longer observed. In 15 patients, a reduction in FEF75 $\geq 15 \%$ was observed as compared to values before TS, whereas no patient showed $\mathrm{a} \geq 15 \%$ reduction in FEV1 or TLC. The mean (SD) reduction in FEF75 tended to be greater in smokers (-11 (9) vs -5.8 (11) \% in nonsmokers), although this difference did not reach statistical significance. Interestingly, in the smoking patients, baseline FEF75 was almost significantly $(p=0.055)$ lower when compared to that of nonsmoking patients: $1.64(0.36) \mathrm{vs}$ $2.14(0.8) \mathrm{L} \cdot \mathrm{s}^{-1}$; (80 (20) vs 94 (34)\% predicted). Furthermore, both in smoking and nonsmoking patients, there was a similar proportion of patients reaching a $\geq 15 \%$ reduction in FEF75: 5 out of 11 vs 9 out of 35 (Chi-squared, $\mathrm{p}>0.05)$.
PFT changes in 35 patients at 6 weeks and 6 months after TS are shown in table 2. TLC had almost completely returned to preoperative values after 6 months. $s R$ aw and s $G$ aw were unchanged, but $R$ aw remained increased (+29\%). At 6 months, FEV1 (-3\%) and FEV1/FVC (-2\%) were slightly but significantly decreased as compared to baseline, and FEF75 also remained disproportionately lower $(-8.6 \%)$. No patient complained of dyspnoea, wheezing, cough, or any other sign or symptom during the 6 months follow-up period.

\section{Discussion}

In this study, the short-term effects of thoracoscopic sympathicolysis on pulmonary function tests were evaluated in 47 patients with EH. Long-term effects on PFTs were obtained in 35 patients. Only very small effects were observed and only on some parameters. Furthermore, all of the patients remained completely asymptomatic.

These results are in marked contrast to the data of MoLHo and co-workers [9, 10] in the only two published reports on PFT changes occurring after surgical D2-D3 sympathectomy for EH. They observed substantial and symptomatic changes in lung volume in all 15 patients studied, and in maximal expiratory flows in 13 of the 15 patients; 1-3 months after surgical supraclavicular sympathectomy, reductions of $15-19 \%$ in mean respiratory volumes and flow rates were seen [9]. These findings were confirmed in a second study, where even more substantial changes were seen after a transaxillary approach [10]; the most notable changes were seen in mean FEF75, which was lowered by $20-25 \%$. The authors ascribed these changes to the (partial) sympathetic denervation of the lung (causing mainly small airways narrowing, unaffected by atropine), although they suggested that the damage due to the thoracotomy itself probably contributed to the reduction in lung volumes, a statement which was supported by BARNES [7]. Indeed, the role of sympathetic innervation of the human lungs is probably limited, although relatively few studies are available in human subjects. Furthermore, important differences in autonomic innervation exist between different species, and simple extrapolation of findings in animal experiments to humans is incorrect [11].

Human airways receive rich postganglionic cholinergic (parasympathetic) innervation, arising from numerous ganglia situated in the airway wall. Preganglionic fibres arise in the brainstem vagal nuclei, and pass through the vagal nerve. Postganglionic fibres innervate smooth muscle cells from trachea to terminal bronchioles [11-13] and submucous glands.

The presence of a certain degree of parasympatheticinduced resting motor tone can be demonstrated by a small bronchodilating response to anticholinergic drugs in normal subjects $[14,15]$. In contrast to the rich parasympathetic nerve supply to airways in all species, sympathetic innervation is generally sparse, although there is considerable variation between species [7, 11]. In humans, direct smooth muscle sympathetic innervation is present but sparse $[13,16,17]$, and greatly outnumbered by the cholinergic nerves. Furthermore, electrical field studies [18-21] suggest that there is no functional sympathetic innervation of human airway smooth muscle, although adrenergic 
nerves may influence bronchomotor tone indirectly by a modulatory influence on cholinergic ganglionic neurotransmission [8]. Nevertheless, beta-adrenoreceptor antagonists have no effect on resting bronchomotor tone in normal humans $[22,23]$. In humans, the only direct neural bronchodilator pathway is provided by the nonadrenergic noncholinergic (NANC) innervation, which probably passes alongside the cholinergic nerves [7, 24]. NANC bronchodilation is predominantly seen in large airways [25]. The bronchodilator effect of anticholinergic drugs is also greater in large than in small airways, whereas betaagonists relax all airways in normals and asthmatics [26, 27].

Thoracoscopic D2-D3 sympathicolysis caused a small, but statistically significant fall in mean TLC $(-3 \%)$ and mean FEV1 (-3\%), and an increase in mean Raw (+12\%). These changes can be ascribed to a "volume-restrictive" effect of the thoracoscopy rather than to a sympathetic denervation effect, because after correction for lung volumes (FEV1/FVC, sRaw, sGaw) all these parameters remained unchanged after sympathicolysis. Indeed, TLC had returned to baseline 6 months after TS, which confirms this hypothesis. The decrease in mean FEF75, an index of small airway function [28, 29], however, is more pronounced (almost $-8 \%$ ) than the decrease in mean TLC and mean FEV1. Furthermore, FEF75 was the only parameter which was reduced by $15 \%$ or more (in 15 out of 47 patients). Finally, the decrease in FEF75, in contrast with the "volume-restrictive" PFT changes, persisted 6 months after TS. These data, therefore, suggest that the decrease in FEF75 may be due to the sympathetic denervation.

FEF75 (flow at low lung volume) is a sensitive test of expiratory flow through small airways [30]. Small airways are defined as the airways distal to the 14th bronchial generation, with an internal diameter of $2 \mathrm{~mm}$ or less. Physiologically, a decrease in small airway calibre ("small airway disease") corresponds with a functional syndrome of discrete perturbations of airway mechanisms in the presence of normal values of "classical" tests of airway obstruction (e.g., FEV1, PEP, Raw). FEF75 is often decreased in smokers [31] and a decrease in FEF75 is one of the earliest indices of the commencement of obstructive airways disease. In our patients, we were able to show that smoking status was not responsible for the observed decrease in FEF75 after TS. Indeed, although baseline FEF75 was lower in smoking patients, mean FEF75 reductions after sympathicolysis were similar in smoking and nonsmoking patients: smoking status, therefore, cannot account for the observed changes in FEF75.

Physiologically, flow at low lung volume is largely determined by the static elastic recoil pressure of the lung and the resistance in smaller "upstream" airways. Therefore, the observed decrease in FEF75 may, theoretically, have been caused by a change in static mechanical properties of the lung itself; the temporary pneumothorax may have caused a change in recoil pressure of the lung, which is an important contributor to the driving pressure of expiratory flow at lung volumes [28]. This is unlikely, however, since at 6 months after the procedure, all volume PFT parameters had returned to baseline values, whereas FEF75 remained unchanged (i.e. decreased as compared to baseline). Furthermore, changes in static lung recoil which have been observed after autonomic modulation (e.g. vagal blockade or inhalation of sympathicomimetic agonists which cause a decrease in static lung recoil) are caused by concomitant changes in peripheral bronchomotor tone itself [35]. However, direct measurement of static lung compliance, thereby evaluating lung recoil pressure, was not performed.

In conclusion, thoracoscopic upper dorsal sympathicolysis in patients with essential hyperhidrosis causes only minimal and subclinical changes in pulmonary function, which can be ascribed, in the main, to a small restriction in pulmonary volume. The latter is probably secondary to the thoracoscopic procedure itself and disappears 6 months after thoracoscopic sympathicolysis. This is in marked contrast to previously demonstrated substantial and symptomatic changes following surgical sympathectomy, which therefore should be abandoned. However, D2-D3 sympathicolysis in itself, and not the thoracoscopic procedure, is probably responsible for a small but significant decrease in maximal expiratory airflow (especially at low lung volume) and increase in airway resistance, suggesting that, at least in essential hyperhidrosis patients, (small) airways bronchomotor tone is influenced by sympathetic innervation. This would resemble the situation in the dog, where thoracic sympathectomy results in a small increase in airway resistance [32], and the effects of pharmacological $\beta$-receptor blockade on airway tone in asthmatics $[33,34]$, but contrasts with the current opinion that airway motor tone in normal humans is not under sympathetic nervous control.

Acknowledgements: The authors gratefully acknowledge the assistance of P. Herregodts in the operating theatre.

\section{References}

1. Harris JD, Jepson RP. Essential hyperhidrosis. Med $J$ Aust 1971; 2: 135-138.

2. Shih CJ, Wu JJ, Lin MT. Autonomic dysfunction in palmar hyperhidrosis. Auton Nerv Syst 1983; 8: 33-43.

3. Claes G, Göthberg G. Endoscopic transthoracic electrocautery of the sympathetic chain for palmar and axillary hyperhidrosis. Br J Surg 1991; 78: 760.

4. Byrne J, Walsch TN, Hederman WP. Endoscopic transthoracic electrocautery of the sympathetic chain for palmar and axillary hyperhidrosis. Br J Surg 1990; 77: 1046-1049.

5. Lin CC. Extended thoracoscopic T2 sympathectomy in treatment of hyperhidrosis: experience with 130 consecutive cases. J Laparoendosc Surg 1992; 2: 1-6.

6. Bannister R, Mathias CJ. Introduction and classification of autonomic disorders. In: Bannister R, Mathias J, eds. Autonomic Failure. A Textbook of Clinical Disorders of the Autonomic Nervous System. 3rd Edn. Oxford, Medical Publications, pp. 1-12.

7. Barnes PJ. Neural control of human airways in health and disease. Am Rev Respir Dis 1986; 134: 1289-1314.

8. Richardson JB, Ferguson CC. Neuromuscular structure and function in the airways. Fed Proc 1979; 38: 202-208.

9. Molho M, Kurchin A, Ohry A, Bass A, Adar R. Pulmonary function abnormalities after upper dorsal sympathectomy. Am Rev Respir Dis 1977; 116: 879-883.

10. Molho M, Shemesh E, Gordon D, Adar R. Pulmonary function abnormalities after upper dorsal sympathectomy. Chest 1980; 77: 651-655. 
11. Richardson JB. Nerve supply to the lungs. Am Rev Respir Dis 1979; 199: 785-802.

12. Partanen M, Laitinen A, Hervonen A, Toivanen A, Laitanen LA. Catecholamine and acetylcholinesterase containing nerves in human lower respiratory tract. Histochemistry 1982; 76: 175-188.

13. Sheppard MN, Kurian SS, Henzen Logmans SC. Neuronspecific enolase and S-100: new markers for delineating the innervation of the respiratory tract in man and other animals. Thorax 1983; 38: 333-340.

14. Vincent NJ, Knudson R, Leith DE, Macklem PT, Mead J. Factors influencing pulmonary resistance. J Appl Physiol 1970; 29: 236-243.

15. De Troyer A, Yernault JC, Rodenstein D. Effects of vagal blockade on lung mechanics in normal man. J Appl Physiol 1979; 46: 217-226.

16. Laitinen A, Partanen M, Hervonen A, Laitinen LA. Electron microscopic study on the innervation of human lower respiratory tract. evidence of adrenergic nerves. Eur J Respir Dis 1985; 67: 209-215.

17. Pack RJ, Richardson PS. The aminergic innervation of the human bronchus: a light and electron microscopic study. J Anat 1984; 138: 493-502.

18. Richardson J, Béland J. Non adrenergic inhibitory nervous system in human airways. $J$ Appl Physiol 1976; 41: 764-771.

19. Davis C, Kannan MS, Jones TR, Daniel EE. Control of human airway smooth muscle: in vitro studies. $J$ Appl Physiol: Respirat Environ Exercise Physiol 1982; 53: 1080-1087.

20. Taylor SM, Pare PD, Schellenberg R. Cholinergic and non adrenergic mechanisms in human and guinea-pig airways. J Appl Physiol: Respirat Environ Exercise Physiol 1984; 56: 958-965.

21. Doidge JM, Satchell DG. Adrenergic and nonadrenergic inhibitory nerves in mammalian airways. $J$ Auton Nerv Syst 1982; 5: 83-90.

22. Tattersfield AE, Leaver DG, Pride NB. Effect of betaadrenergic blockade and stimulation on normal human airways. J Appl Physiol 1973; 35: 613-619.

23. Richardson DS, Sterling GM. Effect of beta-adrenergic receptor blockade on airway conductance and lung volume in normal and asthmatic subjects. BMJ 1969; 3: 143-145.

24. Ichinose M, Inoue H, Miura M, Takishima T. Nonadrenergic bronchodilation in normal subjects. Am Rev Respir Dis 1988; 138: 31-34.

25. Matsumoto N, Inoue $\mathrm{H}$, Ichinose $\mathrm{M}$, Ishii M, Sasaki $\mathrm{H}$, Takishima T. Effective sites by sympathetic beta-adrenergic and vagal nonadrenergic inhibitory stimulation of constricted airways. Am Rev Respir Dis 1985; 132: 1113 1117.

26. Ingram RH, Wellman JJ, McFadden ER, Mead J. Relative contribution of large and small airways to flow limitation in normal subjects before and after atropine and isoproterenol. J Clin Invest 1977; 59: 696-703.

27. Hensley MJ, O'Cain CF, McFadden ER, Ingram RH. Distribution of bronchodilation in normal subjects: betaagonist versus atropine. J Appl Physiol: Respirat Environ Exercise Physiol 1978; 45: 778-782.

28. Robinson DR, Chandhary BA, Speir WA. Expiratory flow limitation in large and small airways. Arch Intern Med 1984; 144: 1457-1460.

29. Pride NB. The assessment of airflow obstruction: role of measurements of airways resistance and tests of forced expiration. Br J Dis Chest 1971; 65: 135-169.

30. Teculescu DB, Sergysels R. Obstruction des voies aériennes périphériques ou maladie des petites bronches. Rev Mal Respir 1986; 3: 349-354.

31. Stanescu DC, Teculescu DB, Pecuraru R, Gavzilescu N. Chronic effect of smoking upon pulmonary distribution of ventilation in healthy males. Respiration 1968; 25: 497-504.

32. Woolcock AJ, Macklem PT, Hogg JC, Wilson NJ. Influence of autonomic nervous system on airway resistance and elastic recoil. J Appl Physiol 1969; 26: 814-818.

33. McNeill RS. Effect of a beta-adrenergic blocking agent, propranolol, on asthmatics. Lancet 1964; 2: 1101-1102.

34. McNeill RS, Ingram CG. Effect of propranolol on ventilatory function. Am J Cardiol 1966; 18: 473-475.

35. Crawford ABH, Makowska M, Engel LA. Effect of bronchomotor tone on static mechanical properties of lung and ventilation distribution. J Appl Physiol 1987; 63: 2278-2285. 